\title{
Proposal of anti-radiation missile decoy assisted by microwave photonics
}

\section{Proposta de distração contra míssil anti-radiação baseada em micro-ondas em fotônica}

André Paim Gonçalves ${ }^{1, *}$, Renan Miranda Richter ${ }^{1}$, Felipe Streitenberger Ivo ${ }^{1}$, Alessandro Roberto Santos ${ }^{1}$, Robson Ribeiro Carreira ${ }^{1}$ Olympio Lucchini Coutinho'

\begin{abstract}
This article has proposed the concept of a decoy that could be used against anti-radiation missiles (ARMs). The bait signals are generated remotely and transmitted to the sacrificial antenna site over a fiber-optic network. This network has the possibility to support broadband radar signals in the range of a few $\mathrm{GHz}$. This study postulated a distance of $1 \mathrm{~km}$ in relation to its park of antennas, distance that may be greater. This analog fiber link was designed for radar signal transmission in the frequency range of 0.3 to $3 \mathrm{GHz}$. The theoretical results were compared with the experimental ones, and it was observed that the behavior of the radar signal power gained in the studied range is straight. Thus, the signal does not present distortions. The system proposed in this study is promising as a distraction for ARMs.
\end{abstract}

Keywords: Decoy, Electronic warfare, Fiber-optic analog link, Radar signals.

\section{RESUMO}

Este artigo propôs o conceito de uma distração que poderia ser utilizada contra mísseis anti-radiação (ARMs). Os sinais a serem emulados são gerados remotamente e transmitidos para o sítio de antenas de sacrifício através de uma rede de fibra óptica. Esta rede tem a possibilidade de suportar sinais de radar com largura de banda de alguns GHz. Este estudo postulou uma distância de $1 \mathrm{~km}$ da estação geradora a seu parque de antenas sacrificiais, tal distância pode ser maior. Este enlace analógico a fibra foi concebido para a transmissão de sinais de radar na faixa de frequências de 0,3 a $3 \mathrm{GHz}$. Os resultados teóricos foram comparados com os experimentais, e observou-se que o comportamento do ganho de potência do sinal de radar para a faixa de frequência estudada é constante. Assim, o sinal não apresenta distorções. O sistema proposto neste estudo é promissor como uma distração para os ARM.

Palavras-chave: Distração, Guerra Eletrônica, Enlace analógico a fibra óptica, Sinais radar. 


\section{INTRODUCTION}

In recent years, a very large spread of operators of anti-radiation missiles (ARMs) is observed, that is, missiles employing their guidance by signals of radio frequency $(\mathrm{RF})$ coming from radars ${ }^{1}$. This work has intended to present a low-cost solution which allows the survival of vital sites of surveillance radar for a certain region. The concept of the use of this protection device against ARMs is based on techniques of transmission of RF signals developed by microwave photonics (MP). The linkage of the RF signals coming from the radar generation and reception station with the antenna site requires high RF bandwidth, low-signal attenuation, immunity to electromagnetic interference and long-operating distance. MP is very promising in meeting all these requirements ${ }^{2}$. Fiber-optic RF signal links are widely known in the literature, but their use as a decoy is poorly studied. This study has proposed the use of RF signal transmitted by fiber optic in order to take advantage of the good results obtained in previous studies presented by MP in RF signal transmission.

The system has intended to use as bait a set of antennas and amplifiers as sacrificial elements to attract ARMs. The signals were generated by the radar to be protected in a sheltered location and far enough away to not be hit by shrapnel. A sample of the signal was transmitted by a fiber-optic network that could branch out to distribute signals to the various sacrificial antennas. This procedure has intended to generate inaccuracy in the missile guidance system.

Using the MP, a link was proposed for transmission of signals from radar with a 1-km fiber-optic channel and which had an optical splitter to divide the signal to its bait antennas, as shown in Fig. 1.

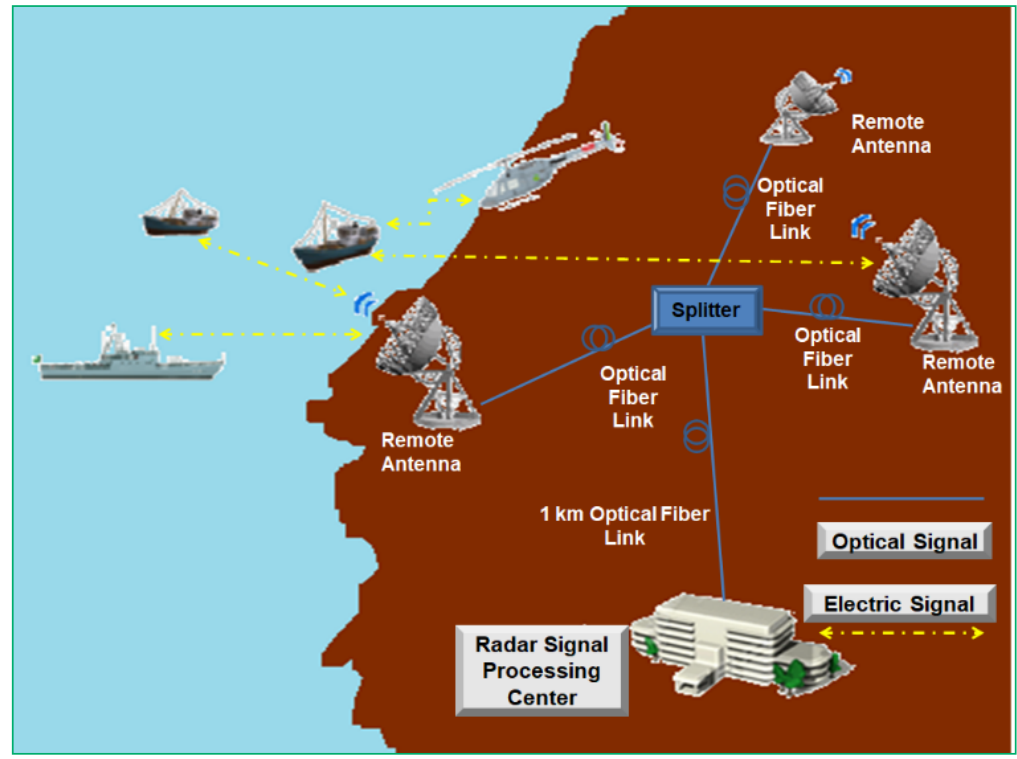

Figure 1: Conceptual representation of the link of radio frequency signals remotely transmitted from a localized radar $(1 \mathrm{~km})$ in relation to the antenna/amplifier sets ${ }^{2}$.

As shown in Fig. 2, this link consisted of a laser diode, impedance matching circuits, a Mach-Zehnder electro-optical intensity modulator (MZM), standard mono (SMF-28) fiber-optic cables, optical splitter, p-i-n type of photodetectors and RF amplifier units $(\mathrm{AU})$.

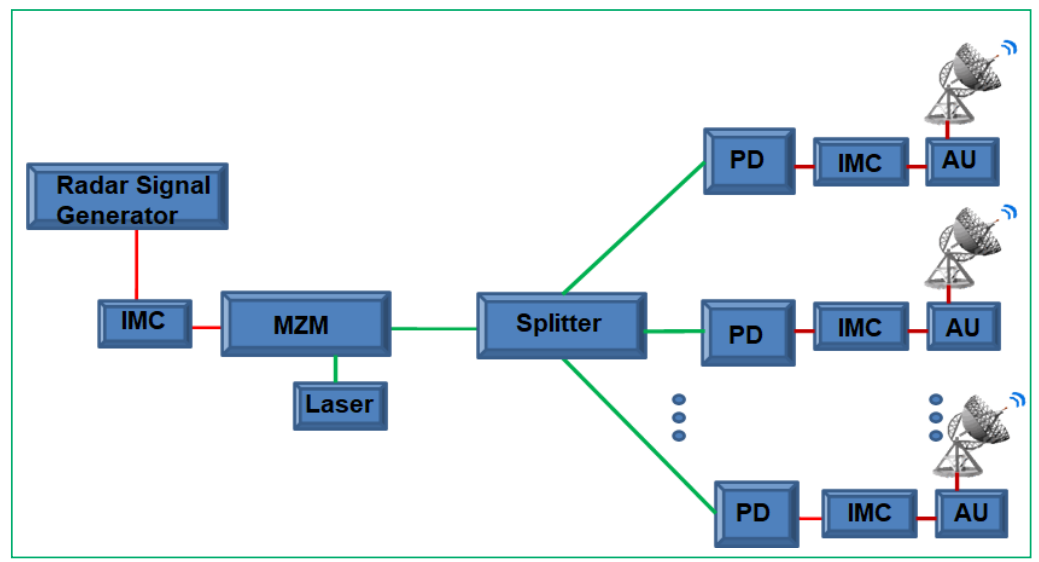

Figure 2: Simplified schematic representation of an antenna system remotely located $1 \mathrm{~km}$ away from the radar generator. The green line means the link in the spectrum optical range and the red in the radio frequency range. IMC: impedance matching circuit; MZM: Mach-Zehnder modulator; PD: photodetector; AU: amplifier unit. 
Observing the elements of the optical network proposed in Fig. 2, it is possible to see the use of an optical splitter without optical amplification.

\section{THEORETICAL ANALYSIS OF THE ANALOGUE LINK TO THE OPTICAL FIBER}

The signal distribution system based on the fiber-optic network must be reliable to the signal generated by the radar to be protected. This fidelity depends on the linearity of the network to transmit the RF signal in order to deceive the missile seeker. The link has non-linear optical elements that have linear operating ranges. For this link, the MMZ and the optical fiber are used within its limits of linear operation.

The MMZ has an optical response corresponding to a quadratic sine. The quadrature point is an inflexion point of the quadratic sine and its vicinity has a linear region to operate. This point is used to avoid non-linearity at modulation. The bias voltage was set to operate at the modulator's quadrature point. The modulation index was chosen equal to 0.10 to ensure the signal works at the linear region around to quadrature point.

The threshold of the Stimulated Brillouin Scattering (SBS) is defined as the necessary power pass from spontaneous to stimulated condition. It is calculated by Eq. 1:

$$
P_{S B S}=21 b_{p} A_{e} /\left(g_{B} L_{e}\right)
$$

in which: $\mathrm{g}_{\mathrm{B}}=$ the maximum Brillouin gain in the steady state; $\mathrm{L}_{\mathrm{e}}=$ the effective length given by Eq. $2 ; \mathrm{A}_{\mathrm{e}}=$ the effective area of the optical fiber; $b_{p}=$ the polarizations related to the pumping and probe laser.

This ratio can be extended to multichannel systems, in which each channel interacts with the fiber regardless the other channels. In Fig. 3, the power threshold variation is showed to avoid the spreading effect of Brillouin.

The $b_{p}$ factor corresponds to the polarizations related to the pumping and probe laser, as well as the polarization properties of the fiber. In a fiber that maintains the polarization with identical states of polarization of the pumping laser and probe, $b_{p}=1$. In $a$ conventional fiber that does not maintain the polarization, $b_{p}=2$, which was considered in this study. The effective length of optical fiber is calculated by Eq. 2 :

$$
L_{e}=\frac{1-e^{-\alpha L}}{\alpha}
$$

in which: $\alpha=$ the fiber loss coefficient $[\mathrm{dB} / \mathrm{km}] ; \mathrm{L}=$ the fiber length.

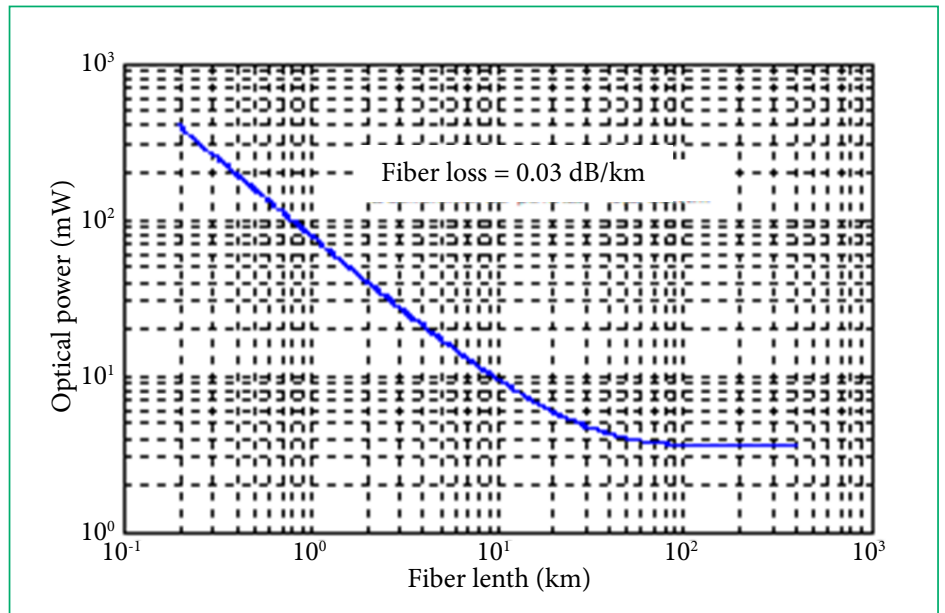

Figure 3: Representation of the power threshold in an optical fiber to avoid the Brillouin scattering phenomenon.

The peak gain coefficient for SBS in single mode fibers is more than two orders of magnitude $\left(\mathrm{g}_{\mathrm{B}}=4 \times 10^{-9} \mathrm{~cm} / \mathrm{W}\right)$ higher than the gain coefficient for Stimulated Raman Scattering (SRS). To ensure that the SRS effect does not occur, it is sufficient to limit the input power to avoid the SBS effect. The SRS effect has its threshold above the SBS. 
The optical fiber depends on the energy level of the optical signal, and the length of the link to be linear. For the purpose of this work, as the length of the link was $1 \mathrm{~km}$ and the optical power available $40 \mathrm{~mW}$, there was a very large margin for the increase of optical power in order to improve the power gain of the RF signal, because $\mathrm{P}_{\mathrm{SBS}}$ is around $70 \mathrm{~mW}$ for a length of $1 \mathrm{~km}^{3-7}$.

In view of these considerations and among the various figures of merit available for the verification of the quality of the link, it was used the analysis of the electrical power gain in $(\mathrm{dB})$, that takes into account all these phenomena.

To determine the behavior of the RF power gain in the link, it was necessary to use the expression of the RF power gain ${ }^{3}$, calculated with the help of the Graf addition theorem given by Equation 3:

$$
G=\frac{4 \eta_{D}^{2} \alpha_{g}^{2}\left(P_{o}^{I n}\right)^{2}}{P_{R F} Z_{L}} J_{1}^{2}\left(2 m_{i} \cos \left(\frac{1}{2} \theta_{d} \omega_{r f}^{2}\right)\right)
$$

in which: $\eta_{\mathrm{D}}=$ the responsiveness of the photodetector; $\alpha_{\mathrm{g}}=$ all optical losses, such as insertion losses; $P_{O}^{I n}=$ the optical input power; $\mathrm{P}_{\mathrm{RF}}=$ the strength of the RF signal at the system input; $\mathrm{Z}_{\mathrm{L}}=$ the impedance of the load; $\mathrm{J}_{1}=$ the representation of the Bessel function of first-order species one; $\mathrm{m}_{\mathrm{i}}=$ the RF modulation index in the MZM; $\theta_{\mathrm{d}}=$ the first-order coefficient of dispersion determined at the angular frequency of the optical carrier, $\omega_{\mathrm{o}} ; \omega_{\mathrm{rf}}=$ the angular frequency of the RF signal;

This expression has been deduced using the Graf addition theorem, that does not approximate the series of Bessel functions that model the operation of the MZM according to the modulation index.

\section{EXPERIMENTAL ANALYSIS OF THE ANALOG LINK TO THE OPTICAL FIBER}

The link was implemented by commercial components. A distributed feedback laser (DFB) laser operating at 1,553.33 nm, MZM with half-wave voltage, V $\pi=4.1 \mathrm{~V} @ 1 \mathrm{GHz}$, a two-output splitter, $1 \mathrm{~km}$ of optical fiber Corning Glass (SMF-28) dispersion of 17 ps/nm.km, two photodetectors for wavelengths from 900 to $1,650 \mathrm{~nm}$ (RF output band >5 GHz) and RF amplifiers (band up to $3 \mathrm{GHz}$, gain min $33 \mathrm{~dB}$ ) were used. These components were assembled according to Fig. 4.

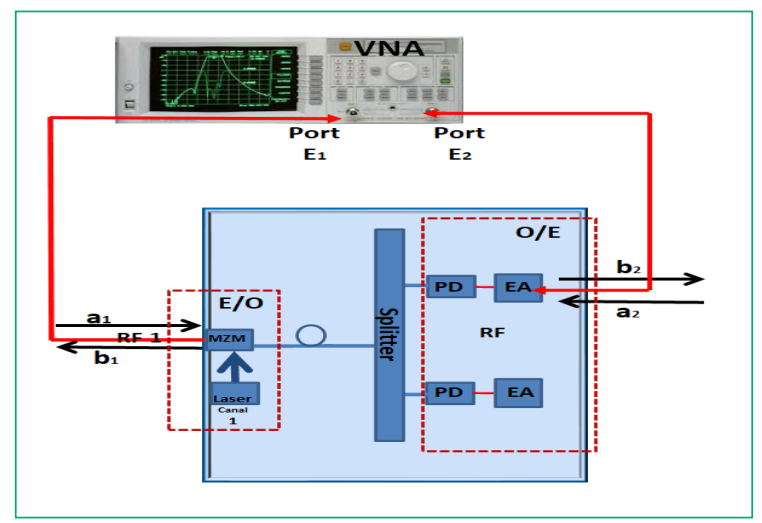

Figure 4: Diagram representing the characterization of the analog fiber-optic link as a radio frequency system by a network analyzer.

VNA: vector network analyzer; E/O: electro-to-optical converter; O/E: optical-to-electro converter; MZM: Mach-Zehnder modulator; PD: photodetector; EA: electronic amplifier.

Firstly, all the components of this system were modeled and characterized experimentally in order to have knowledge of the values involved in each parameter of the link. It should be noted that the values of the parameters of the optical components used in the calculation of the theoretical value of the RF gain were the same as those ones observed in the experimental stage.

After this characterization, in order to measure the power gain of the RF signal of the link, one of the input RF cables of the system to be characterized was connected to port 1 of the network analyzer. The photodetectors were connected to their respective amplifiers. The output cables of the amplifiers were connected one by one to the RF port 2 of the network analyzer. With this procedure, parameter S21 of the RF scattering matrix could be calculated from the fiber-optic link. The RF gain of the system was determined from the voltage values at the output of the RF amplifier for parameter S21 of each channel, discounting the loss represented by the measured result of parameter S21 of the RF cables. Figure 5 shows the comparison of the measured signals for one of the RF outputs overlapping the values calculated by the small signal method and by the exact method applying Graf's theorem. It is important to say that the results measured in each RF output were almost identical in view of the balance of the splitter of almost $50 \%$ in each output port. 
Observing Fig. 5, the overlap of the values obtained in order to compare the calculated results with the measured values shows a very small difference. The measured values were $-32 \mathrm{~dB}$ with a variation of approximately $0.5 \mathrm{~dB}$ in relation to the calculated results. The optical power was settled at $40 \mathrm{~mW}$.

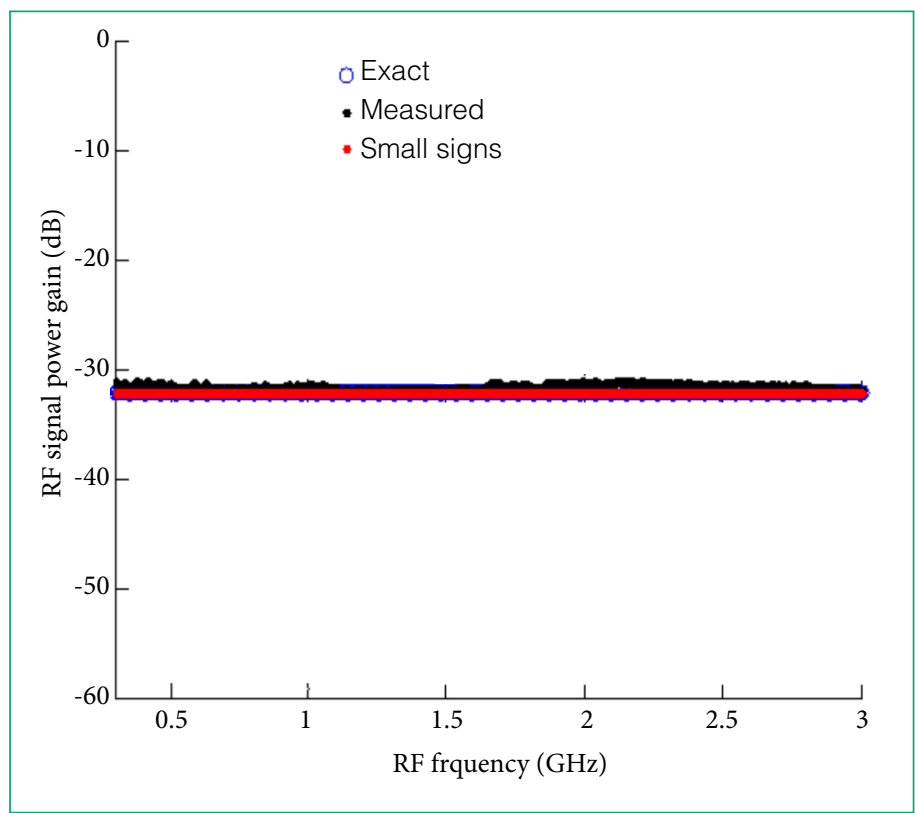

Figure 5: Comparative graph of the measured result with the modulation index $=0.1$ in relation to the one calculated by the small signal method and by the exact method applying Graf's theorem. RF: radio frequency.

In Fig. 6, it was obtained the behavior of a pulsed signal at output of the link with RF amplification, centered at the frequency of $1 \mathrm{GHz}$, in the output of one of the RF ports. The RF signals were generated with a power of $-4.68 \mathrm{dBm}$ (equivalent to the modulation index equals to 0.1 ).

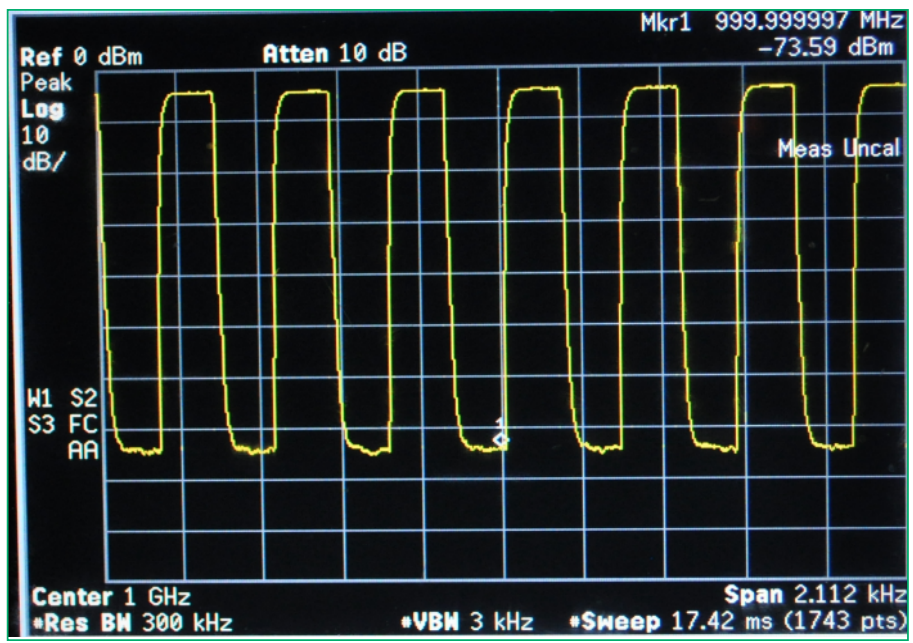

Figure 6: Measurement obtained from the Agilent E4407B spectrum analyzer. The pulse of the radio frequency signal referring to a pulsed signal centered at $1 \mathrm{GHz}$ can be observed with the zero-span feature.

Analyzing Eq. 3, the RF gain depends on the power of the optical carrier and does not consider SBS effect. However, the optical signal strength should not be increased indefinitely. As already shown, when it comes to the transmission of an optical carrier on a fiber optic, the increase in optical power should be limited to avoid the stimulated scattering of Brillouin and Raman, taking into account the length of the link and the optical power according to Eq. 1 . As the length of the link was $1 \mathrm{~km}$ and the optical power $40 \mathrm{~mW}^{3}$, there was a large margin for the increase of optical power to improve the power gain of the RF signal. The gain in the experiment could not be increased, because the laser available for this experiment was limited in power and high losses. The SBS effect was not perceived, considering the match of theoretical and measured gain. 


\section{CONCLUSION}

Linearity may limit the linkage gain to the fiber optics of the RF signal. Observing the results, it can be seen, due to the length of the link of $1 \mathrm{~km}$, that the dispersion and non-linear phenomena of the fiber did not influence the transmission of the RF signals. The RF power gain for this fiber optic link was approximately flat and around $-32 \mathrm{~dB}$ for the frequency range of 0.3 to $3 \mathrm{GHz}$. This flat gain has shown that this link allows large bandwidth of the RF signal. The results for the calculation method applying the Graf addition theorem and the results for the approximation for small signals were almost coincident, considering that, with the modulation index $\left(\mathrm{m}_{\mathrm{i}}\right)$ close to 0.10 , there is no energy transfer from the fundamental component to the harmonics. It should be noted that, if it were necessary to observe the behavior of the RF signals for the case of the larger modulations index, it could be evaluated with this expression developed based on the Graf addition theorem. With this mathematical expression, it became possible to accurately predict the behavior of the power gain of the RF signal. The experiment confirmed theoretical predictions, in which the link is approximately linear thanks to the respect of the optical power limits. This linearity allows the signal fidelity for this application.

With these results, in this initial study, the use of a fiber-optic linkage of RF signals to confuse a seeker of an ARM in this frequency range may make this system possible as a distraction.

\section{REFERENCES}

1. Rim JW, Koh IS. Survivability Simulation of Airborne Platform with Expendable Active Decoy Countering RF Missile. IEEE Trans Aerosp Electron Syst. 2020;56(1):196-207. http://doi.org/10.1109/TAES.2019.2913722

2. Coutinho OL, Almeida VR, Oliveira JEB. Uso de Redes de Comunicações Ópticas para Transmissão e Distribuição de Emissores Radar. In: XIII Simpósio de Aplicações Operacionais em Áreas de Defesa (SIGE), Brazil, São Paulo, São José dos Campos, 2011.

3. Gonçalves AP. Estudo experimental de enlace analógico a fibra óptica empregando WDM e sinal de RF multi-espectral [thesis]. São José dos Campos: Instituto Tecnológico de Aeronáutica; 2014.

4. Jemison WD, Paolella AC. Introduction to Analog Fiber-Optic Links. In: Golio M, ed. RF and Microwave Handbook. 2nd ed. Phoenix: CRC Press; 2008. p. 186-216

5. Kolner BH, Dolfi DW. Intermodulation distortion and compression in an integrated electrooptic modulator. Applied Optics. 1987;26(17):367680. https://doi.org/10.1364/AO.26.003676

6. Halemane TR, Korotky SK. Distortion characteristics of optical directional coupler modulators. IEEE Trans Microw Theory Techn. 1990;38(5):66973. https://doi.org/10.1109/22.54939

7. Singh SP, Singh N. Nonlinear effects in optical fibers: origin, management and applications. Prog Electromagn Res. 2007;73:249-75. http://doi. org/10.2528/PIER07040201 